\title{
Title: The Importance of Screening for Early Detection of Ovarian Cancer: Epidemiological Review
}

\author{
Running Title: Early Detection of Ovarian Cancer
}

Author: Navneetha Hardikar, Department of Biology, Queen's University, Kingston, Ontario

Email: $\underline{\text { n.hardikar@queensu.ca }}$

Phone: 7055294071

\begin{abstract}
Objective: Ovarian cancer, although not possessing a high incidence, is still the most common cancer-related deaths among women diagnosed with a gynecologic malignancy. The present study aims to highlight the epidemiology, risk factors of this disease and the significance of development of improved early detection strategies.

Materials and Methods: This study was conducted using current published English studies by searching PubMed and Google Scholar. The search strategy included the keywords "ovarian cancer", "diagnosis", "risk factors", "screening", "epidemiology". Studies on incidence and mortality were also considered. Case reports were excluded.

Results: The highest incidence and mortality rates are observed in Central and Eastern Europe, while rates are relatively low in Asia and Africa. These rates are highest among the white population (14.3 per 100,000) and lowest among blacks (10 per 100,000) and Asians (9.7 per 100,000). The risk factors for this disease includes a family history, hormonal factors, nutrition and diet and physical activity, with some of them playing protective roles in reducing risk of ovarian cancers. There are no reliable screening methods for ovarian cancers. The most common diagnosis methods include a transvaginal ultrasound and a blood test to detect CA125 markers.

Conclusions: The mortality rate of ovarian cancer is gradually increasing; thus, preventative measures are required to reduce lifetime risk of ovarian cancers and improve mortality rate.
\end{abstract}

KEYWORDS: Ovarian Cancer, Epidemiology, Risk Factors, Screening, Diagnosis, Mortality, Incidence

\section{INTRODUCTION}

Ovarian cancer is the second most common gynecologic malignancy and the most common cancerrelated deaths among women ${ }^{1}$. Most women with ovarian cancer present with advanced stage, which is defined as the metastasize of the tumour to the pelvis or another area in the abdomen². According to the International Federation of Gynaecological Oncologists (FIGO), Stages IIA to IV are advanced. In such cases, the 5 -year overall survival rate is approximately $45 \%^{3}$. However, when the cancer is diagnosed at earlier stages, FIGO Stages I to IIA, the 5 -year survival rate approaches $80 \%{ }^{4}$. Despite recent advances in treatment strategies, relapses occur in most women ${ }^{5}$. The gold standard treatment of advanced ovarian cancer includes cytoreductive surgery and platinum-based chemotherapy. Although there have been improvements in treatment, it has only managed to slightly increase survival; the 10 -year survival rate being approximately $35 \%$, in most countries ${ }^{6}$. In this review, the major risk factors and current screening and diagnosis methods will be discussed to highlight the importance of early detection of ovarian cancer.

\section{MATERIALS AND METHODS}


This review was conducted using current published English full-text articles by searching PubMed and Google Scholar. The search terms included the following keywords: "ovarian cancer", "diagnosis", "risk factors", "screening", "epidemiology". Studies on incidence and mortality were also considered. Case reports were excluded.

\section{RESULTS}

\section{Epidemiology}

There is a geographic variation in the incidence and mortality of ovarian cancer (Table 1$)^{7}$. The highest incidence and mortality rates are observed in Central and Eastern Europe, while rates are relatively low in Asia and Africa. These rates are highest among the white population (14.3 per $100,000)$ and lowest among blacks $(10$ per 100,000$)$ and Asians $(9.7 \text { per 100,000) })^{3}$. The factors that explain the variations in incidence rates and the trends in incidence and mortality include variations in oral contraceptive usage, family history, exercise, and hormonal factors ${ }^{8,9}$. The high incidence of ovarian cancer is associated with increasing age, especially women who are post-menopausal, and the median age at time of diagnosis is 63 years ${ }^{10}$. Ovarian cancer is relatively rare in women below the age of 45 years. Over $80 \%$ of ovarian cancers are observed in women over 45 years of age. In cases where protective factors are absent, the risk of ovarian cancer approaches $2.7 \%{ }^{11}$.

Table. 1. Geographic variation in incidence and mortality rates of ovarian cancer per population of 100,000 as of 2020 (Age-Standardized rate). Drawn from ref. [7].

\begin{tabular}{|l|l|l|}
\hline Geographic Regions & Incidence & Mortality \\
\hline Central and Eastern Europe & 30.7 & 17.2 \\
\hline Northern Europe & 23.8 & 13.2 \\
\hline Southern Europe & 22.5 & 11.7 \\
\hline Northern America & 22.4 & 10.9 \\
\hline South-Eastern Asia & 22 & 14.9 \\
\hline Western Europe & 19.6 & 11.2 \\
\hline Western Asia & 18.8 & 13.6 \\
\hline South-Central Asia & 16.8 & 13.2 \\
\hline Australia and New Zealand & 16.8 & 9.8 \\
\hline Northern Africa & 16.4 & 11.9 \\
\hline Eastern Africa & 16.3 & 13.7 \\
\hline Central America & 16 & 10.6 \\
\hline Western Africa & 15.6 & 13.2 \\
\hline Eastern Asia & 15.5 & 10.7 \\
\hline South America & 15.4 & 9.1 \\
\hline Southern Africa & 12.6 & \\
\hline
\end{tabular}




\begin{tabular}{|l|l|l|}
\hline Middle Africa & 12.6 & 10.7 \\
\hline
\end{tabular}

\section{Risk Factors and Protective Factors}

Although age is a determining factor for risk of ovarian cancer, additional factors, such as those discussed next, may also play a substantial role in increasing ovarian cancer risk.

\section{Family History}

One of the most important risk factors for ovarian cancer is a family history of either breast and/or ovarian cancer. Women whose first-degree relatives are diagnosed with ovarian cancer experience a 3 -fold increase in risk of developing the cancer themselves ${ }^{12}$. In a study on the relative risk (RR) of ovarian cancer in first-degree relatives, the relative risk is higher for first-degree relatives who have been diagnosed at $<50$ years than for those $>50$ (RR 4.7 vs. 2.5, $p=.0052$ ). These results suggest that family history is of great importance when it comes to ovarian cancer incidence rate ${ }^{13}$. Most hereditary ovarian cancers are attributed to BRCA1 and BRCA2 gene mutations ${ }^{14}$. By the age of 80 years, it is estimated that the cumulative risk of ovarian cancer is $44 \%$ in patients who are BRCA1 mutation carriers and $17 \%$ in BRCA2 mutation carriers ${ }^{15}$. Screening for mutations have shown that approximately $15 \%$ of ovarian cancers are associated with BRCA1 and BRCA2 gene mutations ${ }^{16}$.

\section{Hormonal Factors}

Recent studies indicate that use of oral contraceptives is associated with a reduced risk of all histological subtypes of ovarian cancer ${ }^{17-19}$. A case-control study established that oral contraceptive usage is a protective factor for serous ovarian cancer, the most common subtype of ovarian cancer, as it significantly reduced the risk of serous tumour by approximately $60 \%$ compared with patients who have never used oral contraceptives (odds ratio $=0.40 ; 95 \% \mathrm{Cl}: 0.26-0.62)^{20}$. It has been shown that this reduction of risk may last up to 15 years after discontinuation of oral contraceptives ${ }^{21}$.

\section{Diet and Nutrition}

A Canadian case-control study on the link between dietary B-vitamin and ovarian cancer suggested that a diet high in vitamin B6 and folate was inversely associated with the risk of ovarian cancer ${ }^{22}$. An epidemiologic review of the literature suggested that vegetables are highly likely to reduce risk of ovarian cancers ${ }^{23}$. The review also concluded that frequent consumption of whole grain foods and low-fat milk has a protective effect against ovarian cancers.

\section{Physical Activity}

Physical activity has been shown to have a protective effect and thus reduces the risk of ovarian cancer ${ }^{24}$. A Canadian case-control study concluded that moderate to high levels of occupational and recreational activity was associated with a decreasing risk of ovarian cancer ${ }^{25}$. These results may suggest that moderate levels of physical activity decreases ovarian cancer risk and a sedentary lifestyle increases ovarian cancer risk, however, these studies offer inconsistent findings, hence more future studies are required to assess different types of physical activity, while taking into consideration the intensity and duration of activity and their association with ovarian cancer risk ${ }^{26,27}$.

\section{SCREENING AND DIAGNOSIS}


Most often ovarian cancers present with few symptoms during the early stages making it increasingly difficult to diagnose. Some of these symptoms include nausea, abdominal pain, bloating, loss of appetite, and urinary tract issues among others ${ }^{28}$.

An effective strategy for early detection of ovarian cancer is yet to be developed and is one of the main reasons for the delay in diagnosis and treatment of this disease, leading to poor outcomes, lower rates of 5 -year overall survival and high rate of mortality. Only $20 \%$ of ovarian cancer patients are diagnosed at an early stage, with 5 -year survival rates exceeding $90 \%$, compared to late-stage diagnosis that offers 5 -year survival rates of $17-39 \%{ }^{29}$.

The current gold standard screening method is detection of blood serum levels of cancer antigen 125 (CA125). Although this method has been extensively studied, it does not propose valuable results in that these studies have shown low positive values and high rates of false positives causing unnecessary distress to patients and unnecessary surgical interventions $\mathrm{s}^{30}$. There have currently been only 2 trials that investigated the impact of screening on mortality benefit. The largest trial of the two trials was conducted in the UK as part of the UK Collaborative Trial of Ovarian Cancer Screening (UKCTOCS) between 2001 and 2005 with more than 200000 women $^{31}$. The trial randomized the patients to no intervention or annual screening using just the transvaginal ultrasound or serum CA125, interpreted according to the Risk of Ovarian Cancer Algorithm, along with transvaginal ultrasound (multimodal screening). The trial showed a test sensitivity of $86.2 \%$ (95\% Confidence Interval (Cl) 80.8-90.6) with the multimodal screening and 63.3\% (95\% $\mathrm{Cl} 55.4-70.6)$ with transvaginal ultrasound alone. The second trial was the Prostrate, Lung, Colorectal and Ovarian (PLCO) Cancer Screening Trial in the United States ${ }^{32}$. The PLCO trial randomized more than 70000 women to usual care or annual screening for detection of CA125 in blood and transvaginal ultrasound for the first 4 years then 2 years of CA125 only. The PLCO trial resulted in overdiagnosis of low malignant tumours, resulting in these women undergoing surgery. The PLCO trial suggested no significant improvement in ovarian cancer mortality, compared to the UKCTOCS trial which showed a decrease in mortality, however, was not statistically significant. Additionally, the UKCTOCS trial showed a significant stage shift at time of diagnosis in those in the multimodal screening compared to no screening.

Despite these trials, the data does not support the need for screening for ovarian cancers in the general population due to indefinite evidence of mortality benefit. Nevertheless, early detection and screening strategies are continuously being developed. To accurately reduce mortality, it is imperative that future early detection strategies focus on reducing the high false positive rates; risk stratification to improve outcomes in average to high risk women; and identification of other promising biomarkers as a first-line test.

\section{CONCLUSIONS}

Ovarian cancer related deaths are most common in women diagnosed with a gynecologic malignancy with increasing mortality and incidence rate. The difficulty in detecting this disease at an early stage due to lack of symptoms results in an increase in deaths compared to other gynecologic malignancies. The risk factors discussed in this review have been identified as the most common risk factors among women with this disease, with some being protective factors, such as oral contraceptive pills and physical activity, that play a prominent role in reducing the risk of ovarian cancer. The need for improved early detection and screening strategies remains of the utmost importance for reducing early onset of ovarian cancer and improving 5-year overall survival rate. 
The author declares that there are no conflicts of interest.

\section{References}

1. Desai A, Xu J, Aysola K, Qin Y, Okoli C, Hariprasad R, Chinemerem U, Gates C, Reddy A, Danner O, Franklin G, Ngozi A, Cantuaria G, Singh K, Grizzle W, Landen C, Partridge EE, Rice VM, Reddy ES, Rao VN. Epithelial ovarian cancer: An overview. World J Transl Med 2014; 3: 1-8.

2. Colombo N, Sessa C, Bois A, Ledermann J, McCluggage WG, McNeish I, Morice P, Pignata S, Coquard I, Vergote I, Baert T, Belaroussi I, Dashora A, Olbrecht S, Planchamp F, Querleu D. ESMO-ESGO consensus conference recommendations on ovarian cancer: pathology and molecular biology, early and advanced stages, borderline tumours and recurrent disease. Annals of Oncology 2019; 30: 672-705.

3. Ries LAG, Harkins D, Krapcho M, Mariotto A, Miller BA, Feuer ES, Clegg L, Horner MJ, Howlader N, Eisner MP, Richman M, Edwards BK. SEER Cancer Statistics Review, 1975-2004, National Cancer Institute. Bethesa, MD. Accessed 09 April 2021 http://seer.cancer.gov/csr/1975 2004/.

4. Heintz A, Odicino F, Maisonneuve P, Quinn MA, Benedet JL, Creasman WT, Ngan HYS, Pecorelli S, Beller U. Carcinoma of the Ovary. Int Journal of Obstetrics \& Gynaecology 2006; 95: S161-S192.

5. Lopez J, Banerjee S, Kaya SB. New development in treatment of ovarian cancer_future prospective. Annals of Oncology 2013; 24: 69-76.

6. Coleman MP, Forman $\mathrm{D}$, Bryant $\mathrm{H}$. The ICBP module 1 working group cancer survival in Australia, Canada, Denmark, Norway, Sweden, and the UK, 1995-2007 (the international cancer benchmarking partnership): an analysis of population-based cancer registry data. Lancet 2011; 377: 127-138.

7. Ferlay J, Bray F, Pisani P, Parkin DM. GLOBOCAN 2002: Cancer Incidence, Mortality, and Prevalence Worldwide IARC CancerBase No. 5. version 2.0, IARC Press, Lyon, France. 2004.

8. Bray F, Loos AH, Tognazzo S, La Vecchia C. Ovarian cancer in Europe: Cross-sectional trends in incidence and mortality in 28 countries, 1953-2000. Int J Cancer 2005; 113: 977-990.

9. Parazzini F, Franceschi S, La Vecchia C, Fasoli M. The epidemiology of ovarian cancer. Gynecol Oncol 1991; 43: 9-23.

10. Yancik R, Ries LG, Yates JW. Ovarian cancer in the elderly: an analysis of Surveillance, Epidemiology, and End Results Program data. Am J Obstet Gynecol 1986; 154: 639-47.

11. Sopik V, Iqbal J, Rosen B, Narod SA. Why have ovarian cancer mortality rates declined? Part I. Incidence. Gynecol Oncol 2015; 138: 741-749.

12. Stratton JF, Pharoah P, Smith SK, Easton D, Ponder BAJ. A systematic review and metaanalysis of family history and risk of ovarian cancer. Br J Obstet Gynaecol 1998; 105: 493499.

13. Jervis $\mathrm{S}$, Song $\mathrm{H}$, Lee $\mathrm{A}$, et al. Ovarian cancer familial relative risks by tumour subtypes and by known ovarian cancer genetic susceptibility variants. J Med Genet. 2014; 51: 108- 113.

14. Frank TS, Manley SA, Olopade OI, Cummings S, Garber J, Bernhardt E, Antman K, Russo D, Wood ME, Mullineau L, Isaacs C, Peshkin B, Buys S, Venne V, Rowley PT, Loader S, Offit K, Robson M, Hampel H, Brener D, Winer EP, Clark S, Weber B, Strong LC, Thomas A. Sequence analysis of BRCA1 and BRCA2: correlation of mutations with family history and ovarian cancer risk. J Clin Oncol 1998; 16: 2417-2425.

15. Kuchenbaecker KB, Hopper JL, Barnes DR, Philips KA, Mooij TM, Blom-Roos MJ, Jervis S, van Leeuwen FE, Milne RL, Andrieu N, Goldgar DE, Terry MB, Rookus MA, Easton DF, Antoniou 
AC. Risks of breast, ovarian, and contralateral breast cancer for BRCA1 and BRCA2 mutation carriers. JAMA 2017; 317: 2402-2416.

16. Malander S, Ridderheim M, Masback A, Loman N, Kristoffersson U, Olsson H, Nilbert M, Borg A. One in 10 ovarian cancer patients carry germ line BRCA1 or BRCA2 mutations: results of a prospective study in Southern Sweden. Eur J Cancer 2004; 40: 422-428.

17. Tung KH, Goodman MT, Wu AH, McDuffie K, Wilkens LR, Kolonel LN, Nomura AM, Terada KY, Carney ME, Sobin LH. Reproductive factors and epithelial ovarian cancer risk by histologic type: a multiethnic case-control study. Am J Epidemiol 2003; 158: 629-638.

18. Tsilidis KK, Allen NE, Key TJ, Dossus L, Lukanova A, Bakken K, Lund E, Fournier A, Overvad K, Hansen L, Tjønneland A, Fedirko V, Rinaldi S, Romieu I, Clavel-Chapelon F, Engel P, Kaaks R, Schütze M, Steffen A, Bamia C, Trichopoulou A, Zylis D, Masala G, Pala V, Galasso R, Tumino R, Sacerdote C, Bueno-de-Mesquita HB, van Duijnhoven FJ, Braem MG, Onland-Moret NC, Gram IT, Rodríguez L, Travier N, Sánchez MJ, Huerta JM, Ardanaz E, Larrañaga N, Jirström K, Manjer J, Idahl A, Ohlson N, Khaw KT, Wareham N, Mouw T, Norat T, Riboli E. Oral contraceptive use and reproductive factors and risk of ovarian cancer in the European Prospective Investigation into Cancer and Nutrition. Br J Cancer 2011; 105: 1436-1442.

19. Royar J, Becher H, Chang-Claude J. Low-dose oral contraceptives: protective effect on ovarian cancer risk. Int J Cancer 2001; 95: 370-374.

20. Rasmussen ELK, Hannibal CG, Dehlendorff C, Baandrup L, Junge J, Vang R, Kurman RJ, Kjaer SK. Parity, infertility, oral contraceptives, and hormone replacement therapy and the risk of ovarian serous borderline tumors: A nationwide case-control study. Gynecologic Oncol 2017; 144: 571-576.

21. La Vecchia C, Franceschi S. Oral contraceptives and ovarian cancer. Eur J Cancer Prev 1999; 8: 297-304.

22. Arthur RS, Kirsh VA, Rohan TE. Dietary B-Vitamin Intake and Risk of Breast, Endometrial, Ovarian and Colorectal Cancer among Canadians. Taylor \& Francis Online 2019; 71: 10671077.

23. Schulz M, Lahmann PH, Riboli E, Boeing $H$. Dietary determinants of epithelial ovarian cancer: a review of the epidemiologic literature. Nutr Cancer 2004; 50: 120-140.

24. Cottreau CM, Ness RB, Kriska AM. Physical activity and reduced risk of ovarian cancer. Obstet Gynecol 2000; 96: 609-614.

25. Pan SY, Ugnat AM, Mao Y. Physical activity and the risk of ovarian cancer: A case-control study in Canada. Int Journal of Cancer 2005; 117: 300-307.

26. Leitzmann MF, Koebnick C, Moore SC, Danforth KN, Brinton LA, Hollenbeck AR, Schatzkin A, Lacey JV. Prospective study of physical activity and the risk of ovarian cancer. Cancer Causes Control 2009; 20: 765-773.

27. Bertone ER, Willett WC, Rosner BA, Hunter DJ, Fuchs CS, Speizer FE, Colditz GA, Hankinson SE. Prospective Study of Recreational Physical Activity and Ovarian Cancer. JNCl: Journal of the National Cancer Institute 2001; 93: 942-948.

28. Torpy JM, Burke AE, Golub RM. Ovarian cancer. JAMA 2011; 305: 2484-2484.

29. Survival rates for ovarian cancer, by stage. American Cancer Society website. Accessed 11 April 2021 https://www.cancer.org/cancer/ovarian-cancer/detection-diagnosisstaging/survival-rates.html.

30. Lu KH. Screening for ovarian cancer in asymptomatic women. JAMA 2018; 319: 557-558.

31. Jacobs IJ, Menon U, Ryan A, Gentry-Maharaj A, Burnell M, Kalsi JK, Amso NN, Apostolidou S, Benjamin E, Cruickshank D, Crump DN, Davies SK, Dawnay A, Dobbs S, Fletcher G, Ford J, Godfrey K, Gunu R, Habib M, Hallett R, Herod J, Jenkins H, Karpinskyj C, Leeson S, Lewis SJ, Liston WR, Lopes A, Mould T, Murdoch J, Oram D, Rabideau DJ, Reynolds K, Scott I, Seif MW, 
Sharma A, Singh N, Taylor J, Warburton F, Widschwendter M, Williamson K, Woolas R, Fallowfield L, McGuire AJ, Campbell S, Parmar M, Skates SJ. Ovarian cancer screening and mortality in the UK Collaborative Trial of Ovarian Cancer Screening (UKCTOCS): a randomised controlled trial. Lancet 2016; 387: 945-956.

32. Buys S, Partridge E, Greene M, Prorok $P$, Reding D, Riley T, Hartge $P$, Fagerstrom R, Ragard L, Chia D, Izmirlian G, Fouad M, Johnson C, Gohagan J. Ovarian cancer screening in the Prostate, Lung, Colorectal and Ovarian (PLCO) cancer screening trial: Findings from the initial screen of a randomized trial. American Journal of Obstetrics and Gynecology 2005; 193 : 1630-1639. 